\section{Migration: Wall to Wall?}

It is no news to anyone that health transcends national borders, driven by cross-border movement of vectors, populations, health professionals, climate, even policy trends. There is an increasing recognition that it is, in fact, a small world: we are affected by and affect what happens to our neighbors, whether they live around the corner or on the other side of the globe.

This conception underpins the shift from the term international health to global health in policy discussions. The new terminology reflects change across several dimensions:

- from an approach in which there is one medicine for the developed world and another for developing countries, to an appreciation that we all have a stake in one another's wellbeing;

- from a primarily biomedical focus on treatment to a more multidisciplinary, population health focus taking into consideration a range of interventions to improve health and well-being, including the social and environmental determinants of health; and

- from a vertical bilateral-aid approach focused on specific diseases, to systems and ecological approaches addressing the complexities of health, involving multiple partnerships.

The European Commission's Dr Juan Garay summarized it, saying that global health adds "health in all" (emphasizing the multisectoral action needed) and "health by all" (emphasizing participation of multiple partners, including affected communities) to the "health for all" espoused in WHO's constitution.[1]

These conceptual shifts have practical implications, brought into painful relief by two refugee crises, one involving tens of thousands of unaccompanied minors from Central America crossing into the USA from Mexico. The other, when unprecedented numbers of refugees arrived in Europe fleeing conflicts in the Middle East. On World Population Day 2015 (July 11), UNFPA warned that the UN is "fighting a virtually losing battle" against such humanitarian emergencies.[2]

Even wealthy countries are daunted by the challenges of meeting the most basic needs of vast numbers of refugees and immigrants, often compounded by growing xenophobia that threatens the social fabric and worse still, the lives of new arrivals. In both Europe and the United States, loud voices chant for building walls along borders.

At the heart of these crises are the unconscionable disparities that wrack our world: financial markets, trade, communications, conflict and even diseases are globalized. But not so the collaboration needed to take on the challenges of a world where 2.7 billion of our 7 billion people live in abject poverty, and in which the planet itself faces a tenuous future. In 2013, international migrants reached 232 million, accounting for $10.8 \%$ of total population in developed regions, but only $1.6 \%$ in poorer countries. Over half of them live in ten countries, the USA topping the list at $19.8 \%$ of the total.[3]

The 2014 crisis led to further demands for comprehensive US immigration reform, still nowhere in sight. This issue of MEDICC Review-originally cast as an opportunity to explore the range of cross-border health issues - in fact elicited a plethora of manuscripts on migration and the situation of immigrants, primarily from the Global South to the Global North. The people in the following pages reflect a gamut of motives, from fleeing violence to seeking more economic opportunity, or simply looking for health care.

An eminent Cuban demographer reflects on Cuban migration trends in this issue's Interview; and our Reprint examines Cuban immigrants in Canada, their situation an illustration of the effects of Canadian policies on developing-country migration patterns.

Ortega, as well as Landau and Long, present compelling Viewpoints on access to health care in the USA by women and Latinos. Our online Facts \& Figures present data on the health picture of Hispanic/Latino US residents. Research on problems facing diverse North Carolina refugee communities (Sastre and Haldeman) is complemented by an article on asylum seekers in Atlanta (Evans).

Off-theme articles present results from Cuban researchers on genetic variability of HIV-1 (Blanco), the safety of a new conjugate pneumococcal vaccine (González) and early warnings of atherosclerosis (Valdés), along with lessons from a woman-centered lung cancer prevention project (Cruz).

A sidebar is warranted here: On October 28, while this issue of MEDICC Review was in final production, the UN General Assembly once again overwhelmingly voted (191 to 2) to call on the US government to lift its embargo on Cuba. The Secretary General's report to the Assembly went on to detail multiple executive actions available — even with the law still in place-that could substantially benefit both Cuba and the United States in terms of population health. While we applaud these suggestions, we are acutely aware that full cooperation to improve health in both countries can only be achieved once the embargo is ended.

Before closing, congratulations are in order for the well-deserved $\mathrm{PAHO}$ award to Dr María Isabel Rodríguez, member of our Editorial Board, distinguishing her as a Public Health Hero of the Americas. We also welcome three new Board members: Dr Rifat Atun of Harvard University's School of Public Health; Dr Tee Guidotti, environmental health and medicine expert; and Dr Paul C. Erwin of the University of Tennessee's College of Education, Health, and Human Sciences. We look forward to further additions to this important advisory group, essential to the journal's growing readership, impact and relevance to global health equity. - 1 -

\section{The Editors}

1. Garay J, Harris L, Walsh J. Global health: evolution of the definition, use and misuse of the term. Face à face [Internet]. 2013 Oct 16;12 [cited 2015 Oct 20]; [about 5 screens]. Available from: http://faceaface.revues.org/745

2. Deen T. Humanitarian Emergencies Lend Urgency to World Population Day. IPS [Internet]. 2015 Jul 9 [cited 2015 Oct 20]; [about 3 screens]. Available from: http://www.ipsnews.net/2015/07/humanitarian-emergencies-lend-urgency-to -world-population-day

3. UN Department of Economic and Social Affairs. The number of international migrants worldwide reaches 232 million. Population Facts. 2013 Sep;2013/2. http://esa.un.org/unmigration/documents/The_number_of_international _migrants.pdf 